\title{
Design of a miniaturized wideband disc monopole antenna used in RFID systems
}

\author{
Sufyan Hazzaa Ali ${ }^{1}$, Ahmed Hameed Reja ${ }^{2}$, Yousif Azzawi Hachim ${ }^{3}$ \\ ${ }^{1,3}$ Departement of Electrical Engineering, Tikrit University, Iraq \\ ${ }^{2}$ Department of Electromechanical Engineering, University of Technology, Baghdad, Iraq
}

\begin{tabular}{l}
\hline \hline Article Info \\
\hline Article history: \\
Received Jun 15, 2020 \\
Revised Aug 7, 2020 \\
Accepted Aug 21, 2020 \\
\hline
\end{tabular}

Keywords:

Omnidirectional

Partial ground

Patch antenna

RFID

Wideband

\begin{abstract}
Radio-frequency identification (RFID) is an important wireless technology which utilizes radio frequencies (RFs) for exchanging data between two or more points (tags and readers), that represent an automatic identification (Auto-ID) system. This paper introduces an omnidirectional microstrip antenna operates at $2.45 \mathrm{GHz}$ used for a radio-frequency identification (RFID) technology. The length of the proposed antenna is $36.5 \mathrm{~mm}$ and the width is $27 \mathrm{~mm}$. The substrate material which has been used as a base of antenna is FR4 that has dielectric constant value of 4.3 and dielectric thickness value of $1.6 \mathrm{~mm}$. Regarding the resonance frequency, return loss of the proposed antenna design is $-34.8 \mathrm{~dB}$. A promising directivity outcome of $2.8 \mathrm{~dB}$ has been achieved with omnidirectional radiation pattern as well as an acceptable efficiency of $66 \%$. The proposed antenna design accomplishes a wideband frequency of $1.21 \mathrm{GHz}$ in the frequency range of (2.14 - 3.35) GHz. The computer simulation technology (CST) microwave studio software has been used for implementing the proposed antenna design. The antenna design fabricatation and its characteristics have been measured using vector network analyzer (type MS4642A). The obtained results of the experimental design achieve a little bit differences as compared with the simulation results.
\end{abstract}

This is an open access article under the CC BY-SA license.

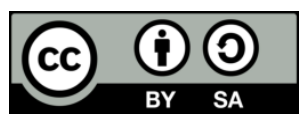

\author{
Corresponding Author: \\ Yousif Azzawi Hachim \\ Department of Electrical Engineering \\ Tikrit University \\ Salah ALdin, Tikrit, Iraq \\ Email: yousifazzawi@st.tu.edu.iq
}

\section{INTRODUCTION}

Radio frequency identification (RFID) is an auto-ID technology that employs electromagnetic (EM) waves to exchange information between readers and tags for tracking and identification [1]. Radio frequency identification in the ultra-high frequencies (RFID UHF) is considered among the emerging technologies in the field of identification, used widely in different areas due to benefits that present as the long read range and miniaturized size [2]. This technology uses radio waves propagation for the communication between the reader and the tags [3]. The RFID technology is applied in several applications such supply chain management, security, access control, tracking and logistics.

A standard RFID system contains tag, reader and its antennas. The reader's antenna transmits a radio frequency (RF) signal to the tag and receives an information signal from it [4]. The RFID system in ultra-high frequency (UHF) band is much important due to its features of fast reading speed, high data transfer rate and long detection in range. Ideally, the frequency band of UHF-RFID system is start from 860 to $960 \mathrm{MHz}$. Several frequency ranges of UHF-RFID bands have been assigned depends on the country, 
location and zone [5]. Thus, design a wideband antenna of reader with desirable performance during the entire band of (860-960) MHz is useful for the RFID system arrangement and enforcement, furthermore cost reduction [6].

There are three typical categories of RFID tags; active, passive and semi-(active / passive) / battery support passive [7, 8]. Every one of these categories has privte features from its inner elements and operation range. The parts of ctive tag are battery and sender that help to transmit the signal that produces an extended and more credible send range. Further, there is no battery and sender in passive tag but it powered by the received signal from the reader by using a backscatter. The semi-active tag reflects the reader signal with backscattering but signal is confirming by exploiting an inner power source batteries [9]. RFID is fastly mounting technology and presents many advantages than conventional identification system such as barcode. The condition of barcode reading is needed to be in line of sight (LOS) between scanner and label where the movement of objects manually or scanner is required [10]. The processes of reading data in RFID technology from tag can do without LOS and also there is no alignment needed. Singh et al. [11] presented a summarized overview of the RFID technology.

In this work, a microstrip antenna has been proposed in order to be resonateed at $2.45 \mathrm{GHz}$ for RFID application. The proposed antenna design is differ from conventional microstip antenna designs where the offered design merges the partial ground technique with omnidirectional radiation. The presented antenna size is $(36.5 \times 27 \times 1.67) \mathrm{mm}^{3}$ which achieves good impedance matching, suitable gain, wide bandwidth, good efficiency, small size and radiation patterns over the complete operating band.

\section{BACKGROUND}

The ideal RFID system contains two RFID subsystems these are tag and reader as shown in Figure 1 [9]. The antenna is one of the important devices in RFID system. RFID is noncontact (wireless) system use radio frequency (RF) through electromagnetic fields (EMFs) as a transmitting channel to carry data from point to other for automatically identifying purposes [12]. The antenna of reader transmits an RF signal to the antenna of tag and receives data from it [9]. The tag contains a chip as an electronic element and antenna where the chip includes the necessary information to identify an object. The reader sends and receives RF energy of the other side (tag) of RFID [7].

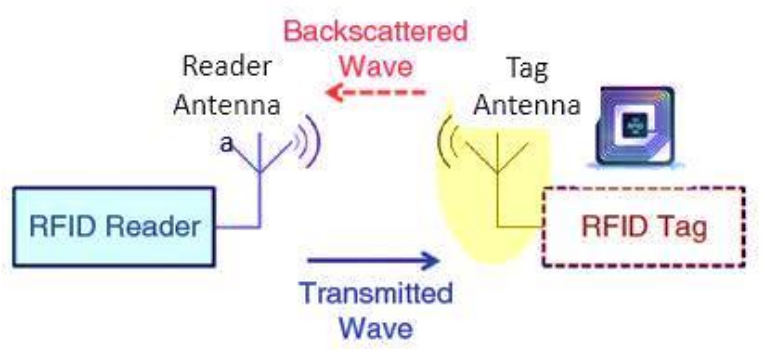

Figure 1. Simple scheme of RFID system

One of the main components in RFID system is antenna that permits to communicate data between tag and reader. RFID system operates on various bands of frequency varies between $30 \mathrm{~Hz}$ and $5.8 \mathrm{GHz}$ with respect to its applications [13, 14]. Internationally, RFID communication is mainly divided into four frequency bands as low frequency $(125-134) \mathrm{KHz}$, high frequency of $13.56 \mathrm{MHz}$, ultra-high frequency (860 960) $\mathrm{MHz}$ and microwave (MW) frequency of $(2.45$ or 5.8) $\mathrm{GHz}$ [15]. However, the microwave (MW) RFID is highly interesting, because the reading range is long, typically $(2-15) \mathrm{m}$ [16]. Recently, RFID technology is wider in applications such in wireless communication (Wi-Fi) [17, 18]. The RFID system consists of two different layers which are physical layer and information technology (IT) layer [16]. Physical layer consists of the followings:

a) One or more radio-frequency (RF) tags

b) One or more interrogators (readers)

c) One or more reader antennas

d) Deployment environment

Information technology (IT) consists of the followings:

a) Hardware such as computers 
b) Networks

c) Software (device drivers, filters, middleware, and user applications)

\subsection{RFID operating principles}

RFID system shown in Figure 2 consists of three components in two combinations: a transceiver (transmitter/receiver) and antenna which usually combined as an RFID reader. A transponder (transmitter/responder) and antenna are combined to make an RFID tag. RFID tag is read when the reader emits a radio signal that activates the transponder, which sends data back to the transceiver. Basic RFID system consists of an antenna or coil, transceiver (with decoder) and a transponder (RF tag) electronically programmed with unique information [19].

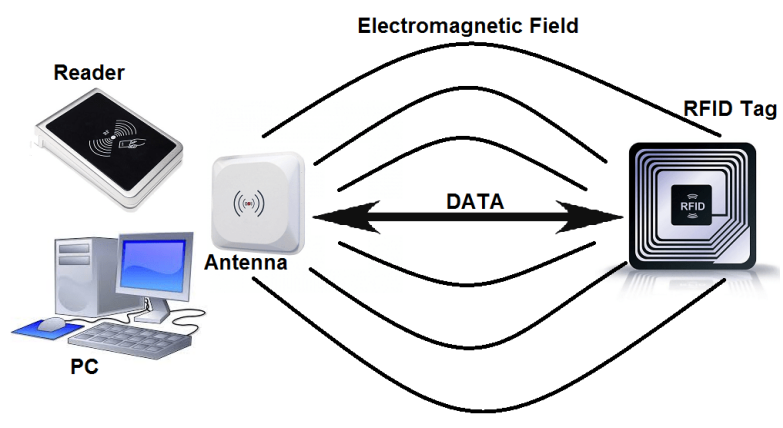

Figure 2. RFID system

The purpose of an RFID system is to enable data to be transmitted by a portable device, called a tag, which is read by an RFID reader and processed according to the needs of a particular application. The data transmitted by the tag may provide identification or location information, or specifics about the product tagged, such as price, color, date of purchase, and so on. A typical RFID tag consists of a microchip attached to a radio antenna mounted on a substrate. The chip can store as much as 2 kilobytes of data [19].

\subsection{Operating frequency}

With the development of Internet of Things (IOT) technology, RFID communication has been widely applied to daily life [20]. Each RF has its private read distance, performance and power requirements. By depending on the application the frequency is choice [2]. RFID systems are operated at widely differing frequencies, ranging from $135 \mathrm{KHz}$ long wave to $5.8 \mathrm{GHz}$ in the microwave range [16]. Internationally, RFID communication is mainly divided into such four frequency bands as low frequency $(125-134) \mathrm{KHz}$, high frequency $13.56 \mathrm{MHz}$, ultrahigh frequency $(860-960) \mathrm{MHz}$ and microwave $(2.45 \mathrm{GHz}$ and above) [15].

\subsection{RFID antennas}

RFID antennas are used to transfer information between tag and reader antennas. RFID antenna kinds are patch antenna, linear polarized antenna, gate antenna and stick antenna. RFID antenna types are shown in Figure 3 [21]. According to the researchers, an RFID antenna should satisfy following requirement [21]: (i) should be small size, (ii) should have omnidirectional coverage or hemispherical coverage, (iii) provides maximum transfer signal, (iv) cheap, (v) robust and (vi) compact.

Microstrip antenna are increasing for use in REID applications especially in UHF band due to their low profile structure and conformal structure [13]. Microstrip patch antenna is printed on substrate material such as FR4 that has three layers; upper side, dilectric and ground plane, where the upper and ground planes are conductors such as copper or gold. A radiating patch can take any credible shape such as triangle, circle, fractal, etc. and is printed in the upper side, while lower side is represented ground plane as shown in Figure 4. The dielectric constant of the substrate $\left(\varepsilon_{r}\right)$ is typically in the range $2.2<\varepsilon_{r}<12$ [22]. For reasonable performance of an antenna, a low dielectric constant or relative permittivity with thick dielectric is suitable to provide best radiation, acceptable efficiency and wide bandwidth [23]. 


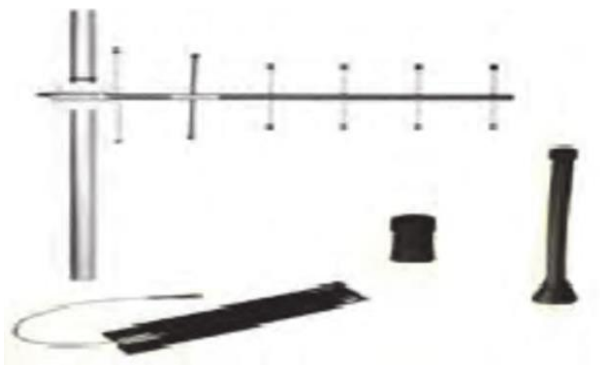

Figure 3. RFID antenna types

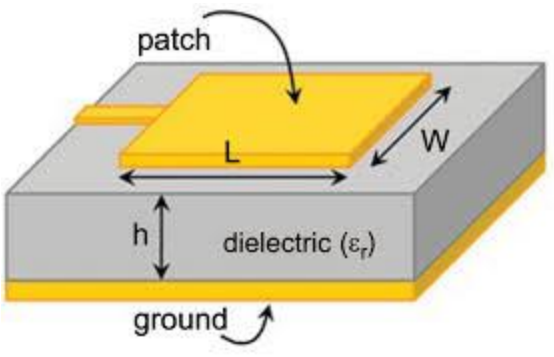

Figure 4. Microstrip patch antenna

\section{RELATED WORK}

The major demerits of the microstrip patch antennas are very narrow bandwidth, low efficiency, high feed network losses and low power handling capacity, which effect on performance of this antenna [2224]. But, on the other side, the microstrip antenna has many merits such small size, low profile, low fabrication cost conformable and easy to build [24]. Many researchers are presently studied several shapes of antenna design used in RFID system by taking a different approach of patch and ground geometry. Generally, the smaller size, best efficiency good directivity and wider bandwidth of RFID antenna system are consider as an important problems of most research. In [25] a type of compact antenna with size of $(30 \times 30 \times 1.6)$ $\mathrm{mm}^{3}$ and narrow bandwidth with acceptable gain has been presented. The return loss bandwidth is $80 \mathrm{MHz}$ in the frequency range of $(2.42-2.5) \mathrm{GHz}$. In [26] designed an antenna to cover dual band 2.4, $5.8 \mathrm{GHz}$ RFID operation frequency bands. The antenna structure likes an F-shaped radiator which has total size of $(38 \times 45$ $\times 1.6) \mathrm{mm}^{3}$ and achieved good realized gain. In [27] a dual band printed omnidirectional antenna operates at $2.45 \mathrm{GHz}$ is presented. The substrate has been used is FR4 and the size of the proposed antenna is $(15 \times$ $85.75) \mathrm{mm}^{2}$ and dielectric thickness of $1.6 \mathrm{~mm}$. The return loss of this antenna at $2.45 \mathrm{GHz}$ is $-10.61 \mathrm{~dB}$ and the bandwidth is $122 \mathrm{MHz}$. The gain that has been realized of this antenna is $3.798 \mathrm{~dB}$. In [28] a compact microstrip stacked patch antenna operates at resonance frequency of $2.45 \mathrm{GHz}$ is proposed for a mobile passive RFID reader. The antenna has dimensions of $(58 \times 58) \mathrm{mm}^{2}$ with large thickness of $11 \mathrm{~mm}$. The narrow bandwidth with frequency range from 2.31 to $2.56 \mathrm{GHz}$ and the peak gain achieved of $6.32 \mathrm{~dB}$ in the resonance frequency $2.45 \mathrm{GHz}$ was presented. In [29] a single layer passive RFID tag antenna containing a pair of $\mathrm{T}$ and $\mathrm{U}$ slots cut on a square microstrip patch with an operating frequency of $2.45 / 2.41 \mathrm{GHz}$ was proposed. Dimensions of this antenna are $(35 \times 35) \mathrm{mm}^{2}$ in which the proposed antenna has bandwidth of $250 \mathrm{MHz}$ and the gain of approximate to $2.1 \mathrm{~dB}$. In [30] an antenna operated at $2.45 \mathrm{GHz}$ with the overall size of $(35 \times 26 \times 1.67)$ produced gain of $2.5 \mathrm{~dB}$ at $2.415 \mathrm{GHz}$ was presented. In [31] a new miniature microstrip antenna with size of $(21.22 \times 32.05) \mathrm{mm}^{2}$ and directivity of $1.91 \mathrm{~dB}$. The bandwidth is equal to $327 \mathrm{MHz}$.

The solution of the main problems for the design of the proposed microstrip antenna are to achieve small size with wide bandwidth and suitable value of gain in addition to achieve best return loss value and VSWR that lead to get best performance for microstrip antenna. Many techniques are used to design a miniature antenna, as the slot technique [32-35], the fractal structure, the Defected Ground Structure (DGS) [36], or the use of metamaterial structure [37].

\section{ANTENNA DESIGN AND GEOMETRY}

The configuration of the proposed antenna is illustrated in Figure 3. The RFID antenna consists of a patch antenna as switch shape with balanced feed and partial ground antenna to achieve omnidirectional radiation pattern. It is printed on a suitable cost FR4 substrate material, whose relative permittivity, loss tangent, and thickness are 4.3, 0.025 and $1.6 \mathrm{~mm}$, respectively. The slots size at the back sides and back middle of the antenna consist the dimensions of $(1.5 \times 14) \mathrm{mm}$ and $(23 \times 0.25) \mathrm{mm}$, respectively. The comprehensive size of the general microstrip patch antenna has been determined as in ref. [22]. The width of the antenna structure depends on the speed of light in free space $\left(v_{o}\right)$, relative permittivity $\left(\varepsilon_{r}\right)$ and the resonate frequency $\left(f_{r}\right)$ and it is calculated as (1).

$$
W=\frac{1}{2 f_{r} \sqrt{\mu_{o} \varepsilon_{o}}} \sqrt{\frac{2}{\varepsilon_{r}+1}}=\frac{v_{o}}{2 f_{r}} \sqrt{\frac{2}{\varepsilon_{r}+1}}
$$

Where $v_{o}=3 \times 10^{8} \mathrm{~m} / \mathrm{s}$, 
$\mu_{o}=4 \pi \times 10^{-7} \mathrm{H} / \mathrm{m}$

and $\varepsilon_{o}=8.85 \times 10^{-12} \mathrm{~F} / \mathrm{m}$

The effective dielectric constant in the line $\left(\varepsilon_{e f f}\right)$ in this case is calculated as (2):

$\varepsilon_{e f f}=\frac{\varepsilon_{r}+1}{2}+\frac{\varepsilon_{r}-1}{2}\left[1+\frac{12 h}{W}\right]^{-1 / 2}$

The length of antenna increases due to fringing effect as (3):

$$
\frac{\Delta L}{h}=0.412 h \frac{\left(\varepsilon_{e f f}+0.3\right)\left(\frac{W}{h}+0.264\right)}{\left(\varepsilon_{e f f}-0.258\right)\left(\frac{W}{h}+0.8\right)}
$$

$\Delta \mathrm{L}$ is the extended patch length in each end due to fringing

The effective length is calculated by (4):

$$
L_{e f f}=\frac{1}{2 f_{r} \sqrt{\varepsilon_{r e f f}} \sqrt{\mu_{o} \varepsilon_{o}}}=\frac{v_{o}}{2 f_{r} \sqrt{\varepsilon_{r e f f}}}
$$

The patche's actual length $\left(L_{\text {act. }}\right)$ is obtained by (5).

$$
L_{\text {act. }}=L_{\text {eff }}-2 \Delta L
$$

The dimensions of the base of substrate material that represented as ground plane, width $\left(W_{\mathrm{g}}\right)$ and length $\left(L_{\mathrm{g}}\right)$ are obtained as $(6)$ and (7).

$$
\begin{aligned}
& W_{\text {substrate }}=W+6 h \\
& L_{\text {substrate }}=L+6 h
\end{aligned}
$$

By using the above equations the dimensions of antenna is achieved as shown in Figure 5. The design parameters are listed in Table 1.

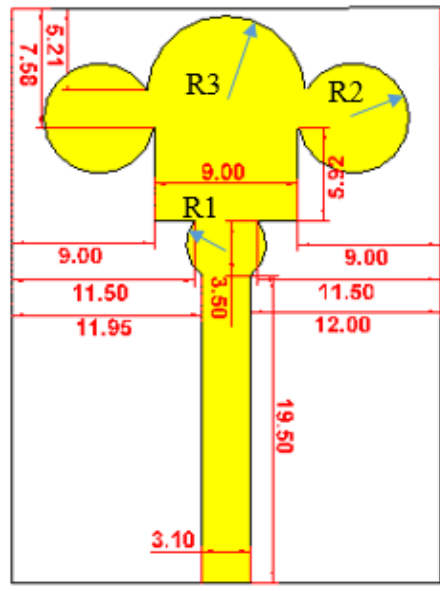

(a)

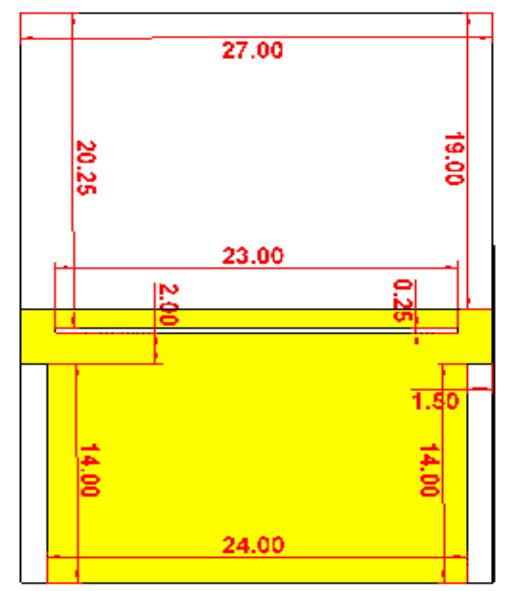

(b)
Table 1. Dimensions of the proposed antenna

\begin{tabular}{cc}
\hline Parameter & $\begin{array}{c}\text { Dimension } \\
(\mathrm{mm})\end{array}$ \\
\hline Substrate width & 27 \\
Substrate length & 36.5 \\
$R_{I}, R_{2}, R_{3}$ & $2.5,3.5,5$ \\
Feed width & 3.1 \\
Feed length & 19.5 \\
Conductor & 0.035 \\
thickness & \\
Ground width & 27 \\
Ground length & 17.5 \\
Dielectric height & 1.6 \\
\hline
\end{tabular}

Figure 5. Antenna design (a) patch, (b) ground plane

\section{SIMULATION RESULTS AND DISCUSSION}

Initially, the return loss $\left(\mathrm{S}_{11}-\mathrm{dB}\right)$ can be obtained with respect to frequency as in Figure 6 . the minimum dip in response is $-34.8 \mathrm{~dB}$ accured at $2.45 \mathrm{GHz}$. 


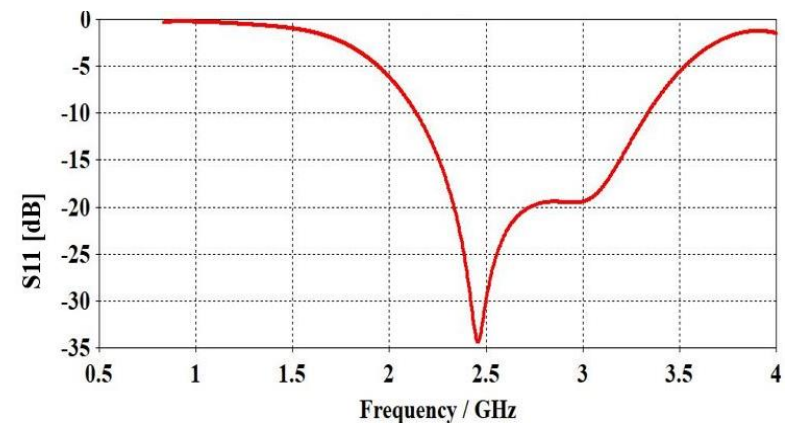

Figure 6. Return loss response

Calculation of Bandwidth (BW)

Lower frequency $\left(f_{L}\right)=2.14 \mathrm{GHz}$

Higher frequency $\left(f_{H}\right)=3.35 \mathrm{GHz}$

Center frequency $\left(f_{r}\right)=2.45 \mathrm{GHz}$

$$
\begin{aligned}
& B W \%=\frac{f_{H}-f_{L}}{f_{r}}(8) \\
& B W \%=49.38 \%
\end{aligned}
$$

As can be observed from Figure 4, the minimum return loss value of the disc monopole antenna is about $-34.8 \mathrm{~dB}$ at the resonance frequency $(2.45 \mathrm{GHz})$. The bandwidth of proposed antenna is $1.21 \mathrm{GHz}$ in the frequency range of $(2.14-3.35) \mathrm{GHz}$. In this work, it obvious that the presented antenna is appropriate for RFID applications in a wide band range of frequencies. The other decisive parameter beside the return loss (RL), that is concerning the bandwidth (BW) and effects on the antenna performance, is voltage standing wave ratio (VSWR). In fact it is limited in range, $1 \leq V S W R \leq 2$. Thus, the antenna can be capable to operate at frequencies where the value of VSWR is below than 2 [38]. The VSWR curve of the designed antenna is shown in Figure 7.

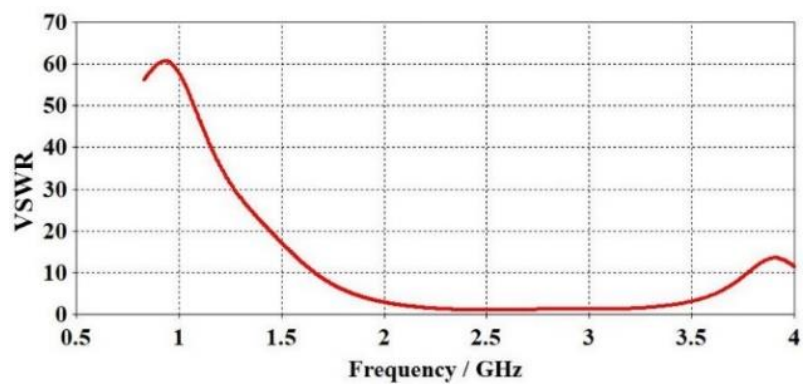

Figure 7. VSWR verses frequency

From Figure 7, it can be seen that the VSWR value of the proposed antenna at $2.45 \mathrm{GHz}$ is about 1.08. As clarified from the frequency response in Figure 8 of the designed antenna, an appreciable gain value of $1.85 \mathrm{~dB}$ is obtained. The other considerable parameter related to gain, that interested in antenna performance is the directivity (D). Figure 9 offers the radiation pattern and directivity of the presented antenna. Theoretically, the relation between the gain $(\mathrm{G})$ and directivity (D) is associated to antenna efficiency factor $(\eta)$ as in (9).

$$
G=\eta D(9)
$$

The antenna efficiency factor $(\eta)$ value is enclosed by $(0 \leq \eta \leq 1)$. If the efficiency factor equals 1 , then the antenna is lossless and practically, the gain $(G)$ is less than the directivity (D). As spotted in Figure 9 , the incident power in generally is radiated with less back lobe while the maximum directivity $\left(D_{\max }\right)$ observed from Figure 9 is $2.8 \mathrm{~dB}$. The simulation results of the proposed antenna are extracted and collected in Table 2. 

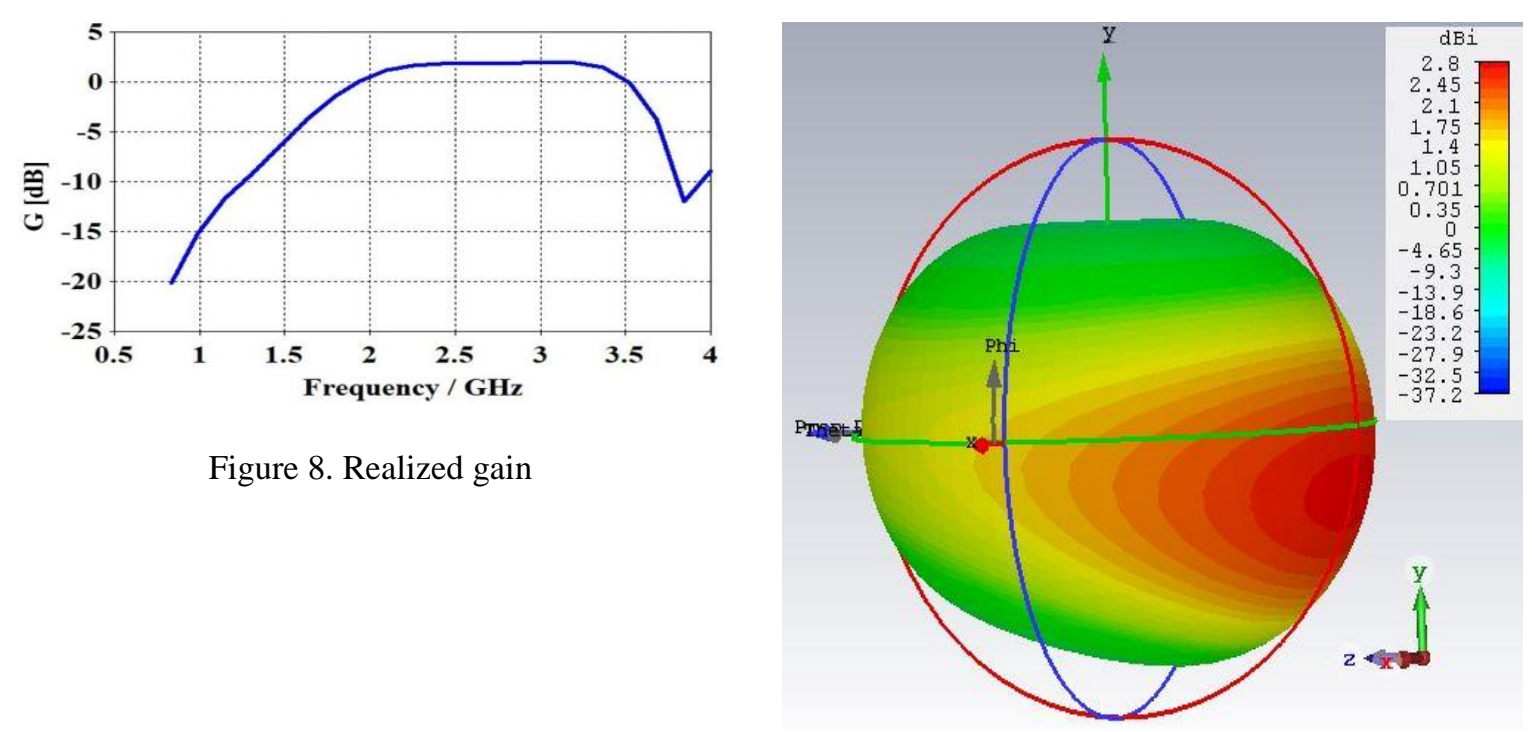

Figure 9. Radiation pattern with directivity

Table 2. Extracted simulation results of the proposed antenna

\begin{tabular}{cc}
\hline Parameters & Value \\
\hline Frequency band $(\mathrm{GHz})$ & $2.14-3.35$ \\
Resonant frequency $(\mathrm{GHz})$ & 2.45 \\
Bandwidth $(\mathrm{GHz})$ & 1.21 \\
Return loss $(\mathrm{dB})$ & -34.8 \\
VSWR in minimum case & 1.08 \\
Gain $(\mathrm{dB})$ & 1.85 \\
Directivity $(\mathrm{dB})$ & 2.8 \\
\hline
\end{tabular}

To support this work the many useful parameters has been clarified such as surface current, radiation pattern and antenna input impedance as in the following subsections.

\subsection{Surface current}

In order to clarify the essence of the frequency band characteristic, the surface current distribution at the resonance frequency on the upper side represented as a patch and the ground plane is simulated, Figure 10 illustrate this behavior. From Figure 10, the current distribution is concentrated around the feedline and on the starting patch in addition in the middle ground slot, after that the surface current begin to spread gradually in patch and ground plane.

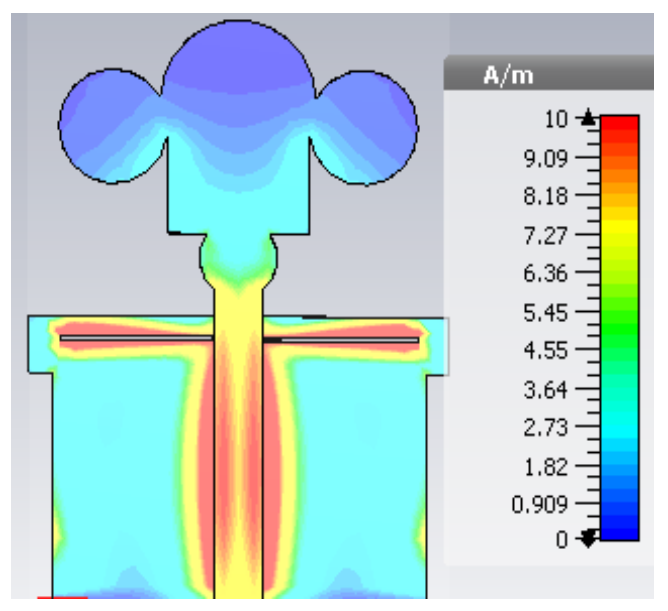

Figure 10. Surface current distribution 


\subsection{Radiation pattern}

Figure 11 shows the simulated radiation patterns when phi $=0^{\circ}$ and theta is varied from $0^{\circ}$ to $180^{\circ}$ at $2.45 \mathrm{GHz}$. The proposed antenna provides an omnidirectional radiation pattern in the E-plane with main lobe direction at $180^{\circ}$, while provides directional pattern in H-plane at main directional pattern of $180^{\circ}$.

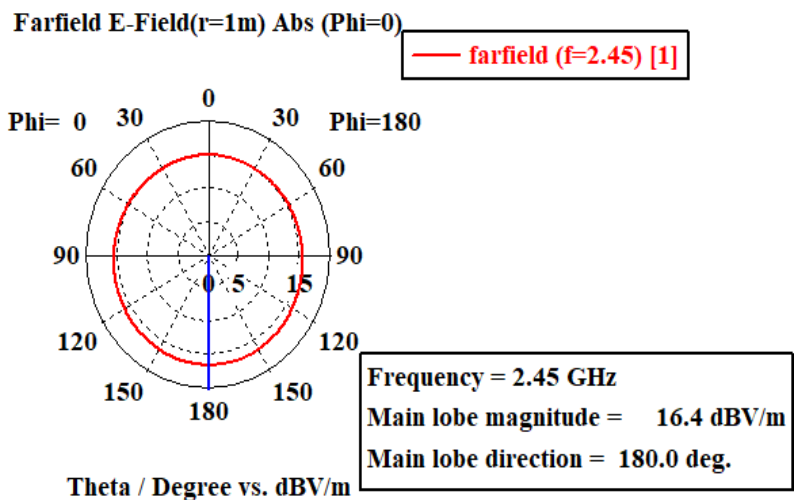

(a)

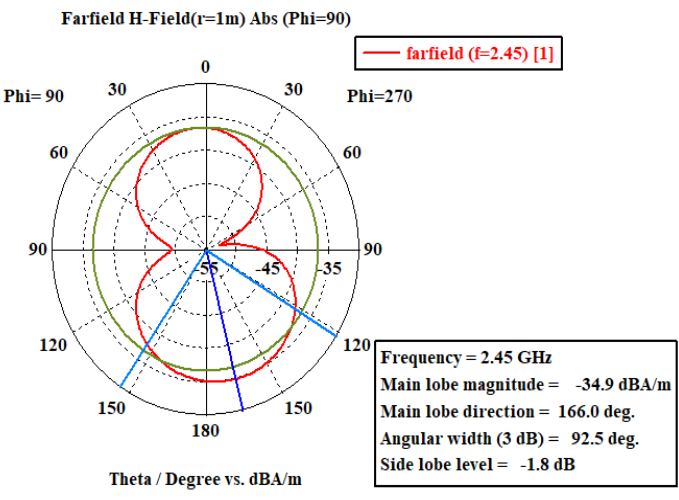

(b)

Figure 11. Field patterns (a) E-Field at $\mathrm{phi}=0^{\circ}$, and (b) $\mathrm{H}$-Field at phi $=90^{\circ}$

\subsection{Antenna impedance}

The behavior of the proposed antenna for real and imaginary parts impedance of is shown in Figure 12. In the resonant frequency $(2.45 \mathrm{GHz})$ the input impedance of the proposed antenna is $(49.8+\mathrm{j} 1.2) \Omega$, that gives a good impedance matching between transmission line and antenna.

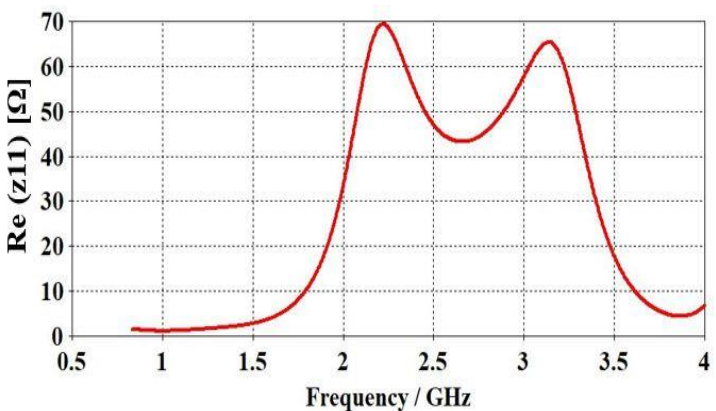

(a) Real impedance

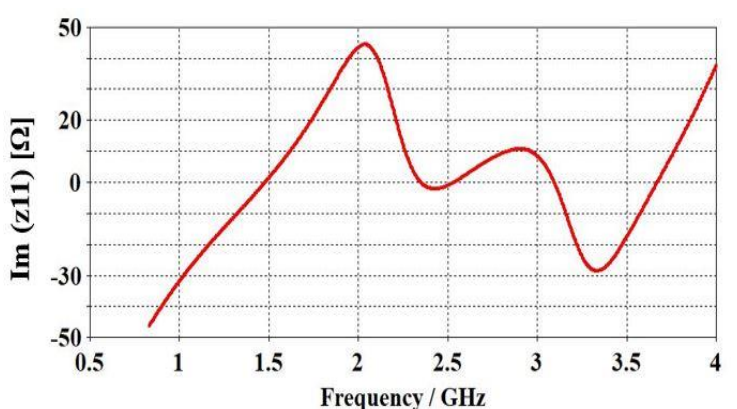

(b) Imaginary impedance

Figure 12. Simulation input resistance (a) real part, (b) imaginary part

\section{MANUFACTURED ANTENNA AND RESULTS}

Figure 13 shows the fabrication of the proposed antenna and its test and measured operation using vector network analyzer (VNA) type MS4642A. The simulated and measured results of return loss characteristics of the proposed antenna are illustrated in Figure 14. As can be observed from the experimental and simulation cases, a good and agreement return loss has been obtained. The measured and simulated VSWR are illustrated in Figure 15. The measured VSWR agrees well with the simulated one and equal to 1.08 at $2.45 \mathrm{GHz}$. Figures 16 and 17 show the measured and simulated of real impedance and imaginary impedance, respectively. It is observed from these figures that the results in case of simulation and measurement are relatively good agreement with each other.

As compared the proposed antenna design with the state of art relevant works, the proposed design achieves smaller size with wide bandwidth and best return loss as well as an omnidirectional radiation pattern. All these characteristics results show that proposed design outperforms the other relevant works designs. Table 3 summarizes the the proposed antenna design outcomes as compared with the other state of art works design. 


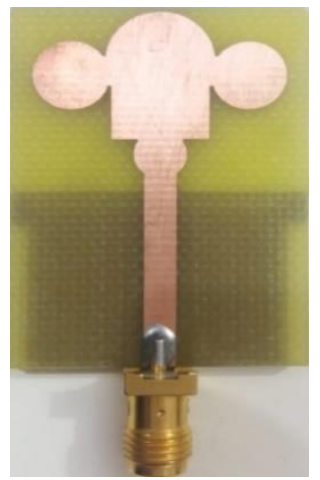

(a)

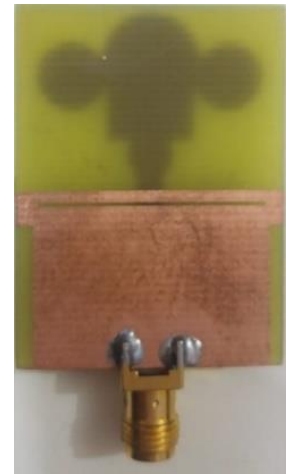

(b)

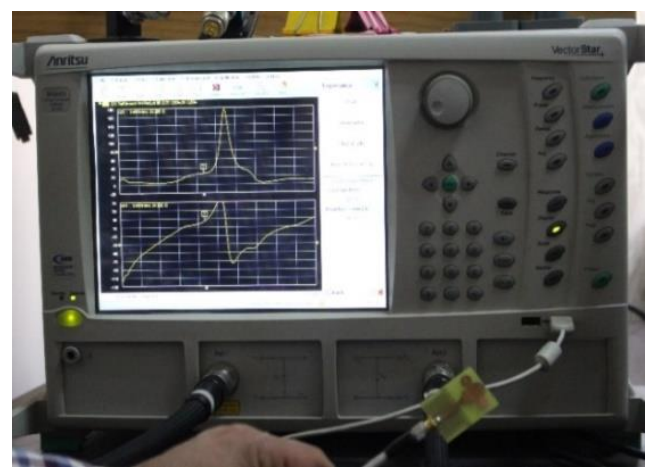

(c)

Figure 13. Fabricated of the proposed antenna (a) patch plane, (b) ground antenna, (c) measured operation using VNA (type MS4642A) and test

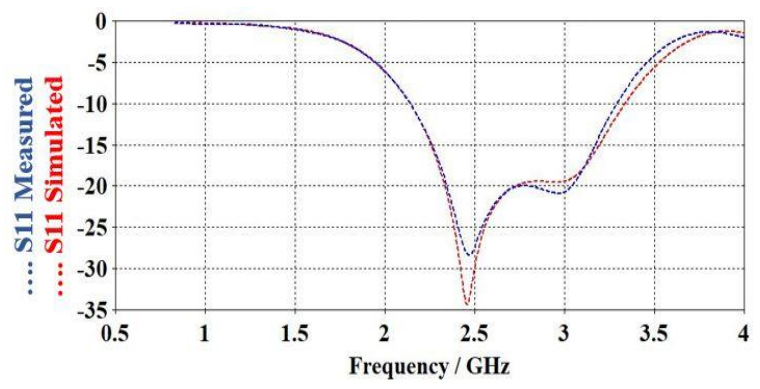

Figure 14. Simulated and measured results of antenna return losses

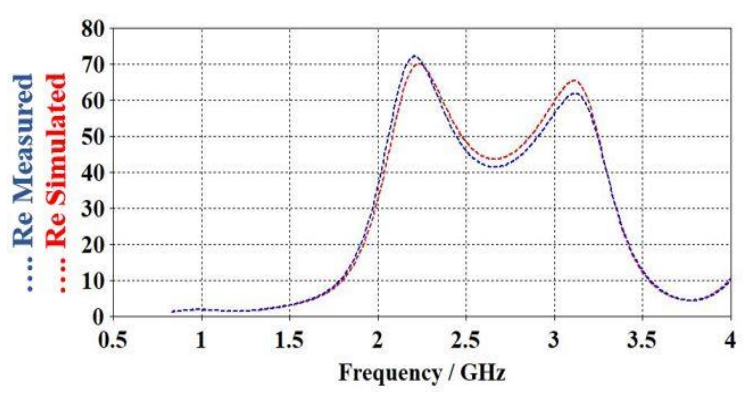

Figure 16. Simulated and measured results of antenna real impedance

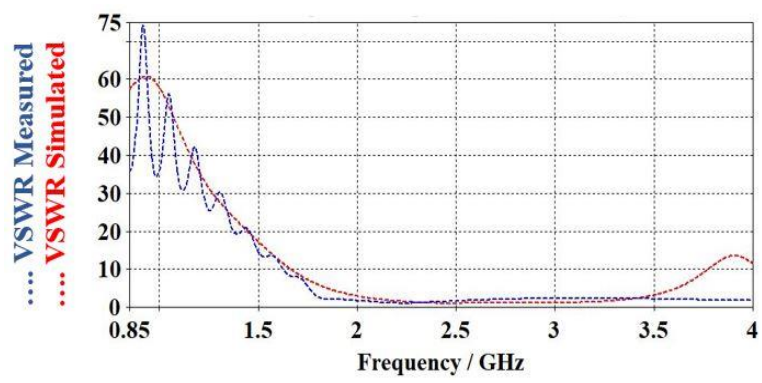

Figure 15. Simulated and measured results of antenna VSWR

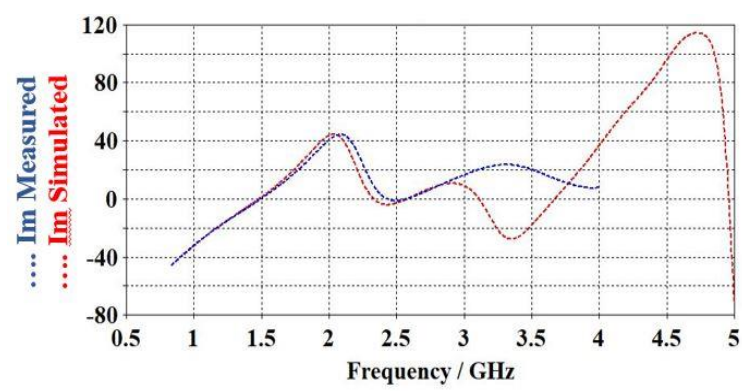

Figure 17. Simulated and measured results of antenna imaginary impedance

Table 3. Comparsion of this design with the other designs

\begin{tabular}{llll}
\hline Methods & Dimensions $\left(\mathrm{mm}^{2}\right)$ & Bandwidth $(\mathrm{MHz})$ & Return Loss $(\mathrm{dB})$ \\
\hline$[27]$ & $30 \times 30$ & 80 & 17 \\
{$[28]$} & $38 \times 45$ & Narrow bandwidth & 20 \\
{$[29]$} & $15 \times 85.75$ & 122 & 10.61 \\
{$[30]$} & $58 \times 58$ & 250 & 55 \\
{$[31]$} & $35 \times 35$ & 250 & 50 \\
Proposed antenna & $27 \times 36.5$ & 1210 & 34.8 \\
\hline
\end{tabular}

\section{CONCLUSION}

In this paper, a partial ground with slot in the ground plane of antenna is presented to operate at 2.45 $\mathrm{GHz}$ for universal ultra-wideband RFID applications. By using a partial ground theory with rectangular slot 
and switch shaped radiator in antenna design, a desired performance of gain, reflection coefficient, efficiency and wide bandwidth over the frequency range from 2.14 to $3.35 \mathrm{GHz}$ is improved compared with conventional one. The radiation of the proposed antenna is omnidirectional radiation pattern. The results of the proposed antenna at less than $10 \mathrm{~dB}$ return loss are bandwidth of $1.21 \mathrm{GHz}$, VSWR of 1.08 and maximum measured gain of $1.85 \mathrm{~dB}$. The measurement results agree well with the corresponding simulated ones. The structure of the proposed antenna is attractive in addition to easy to design and fabrication. The proposed antenna has several advantages such as a very wide impedance bandwidth, omnidirectional radiation, and small size.

\section{REFERENCES}

[1] Q. Liu, J. et al, "Compact 0.92/2.45-GH dual-band directional circularly polarized microstrip antenna for handheld RFID reader applications," IEEE Trans. Antennas Propag., vol. 63, no. 9, pp. 3849-3856, 2015.

[2] D. Parkash, T. Kundu, and P. Kaur, "The RFID Technology and ITS Applications: A Review," Int. J. Electron. Commun. Instrum. Eng. Res. Dev., vol. 2, no. 3, pp. 109-120, 2012.

[3] K. Finkenzeller and R. Waddington, RFID Handbook, 2nded., pp.161-181, John Wiley and L. Sons, 2003.

[4] W.-S. Chen and Y.-C. Huang, "A novel CP antenna for UHF RFID handheld reader," IEEE Antennas Propag. Mag., vol. 55, no. 4, pp. 128-137, 2013.

[5] C. Raviteja, C. Varadhan, M. Kanagasabai, A. K. Sarma, and S. Velan, "A fractal-based circularly polarized UHF RFID reader antenna," IEEE Antennas Wirel. Propag. Lett., vol. 13, pp. 499-502, 2014.

[6] J. H. Lu and S. F. Wang, "Planar broadband circularly polarized antenna with square slot for UHF RFID reader," IEEE Trans. Antennas Propag., vol. 61, no. 1, pp. 45-53, 2013.

[7] C.-H. Chiang, T.-H. Cheng and S.-Y. Chen, "A compact RFID tag antenna using miniaturized patch structure for metallic object applications," in 2014 IEEE Antennas and Propagation Society International Symposium (APSURSI), pp. 1510-1511, 2014.

[8] V. Chawla and D. S. Ha, "An overview of passive RFID," IEEE Commun. Mag., vol. 45, no. 9, pp. 11-17, 2007.

[9] A. Fahmy, H. Altaf, A. Al Nabulsi, A. Al-Ali and R. Aburukba, "Role of RFID technology in smart city applications," 3rd Int. Conf. Commun. Signal Process. their Appl. ICCSPA 2019, pp. 1-6, 2019.

[10] R. Cronin, "RFID versus Barcode," Pharm. Technol., vol. 32, no. 11, pp. 177-178, 2008.

[11] S. P. Singh, M. McCartney, J. Singh and R. Clarke, "RFID research and testing for packages of apparel, consumer goods and fresh produce in the retail distribution environment," Packag. Technol. Sci. An Int. J., vol. 21, no. 2, pp. 91-102, 2008.

[12] A. Kaur, "Electronically Steerable planer Phased Array," International Journal of Engineering Trends and Technology, vol. 3, no. 6, pp. 708-713, 2012.

[13] R. A. R. Ibrahim and M. C. E. Yagoub, "Practical novel design component of microstrip patch slot antenna MSPSA for RFID applications," in CCECE 2010, pp. 1-5, 2010.

[14] Y.-Y. Lu, S.-C. Wei and H.-C. Huang, "Design of RFID antenna for $2.45 \mathrm{GHz}$ applications," in 4th Int. Conference on Innovative Computing, Information and Control (ICICIC), pp. 601-604, 2009.

[15] B. Zhao and H. Zhang, "Application and development of RFID technique [J]," Electron. Des. Eng., vol. 10, 2010.

[16] K. Finkenzeller, RFID handbook: fundamentals and applications in contactless smart cards, radio frequency identification and near-field communication, 3rd ed. U. K.: John wiley \& sons, 2010.

[17] J. K. Pakkathillam and M. Kanagasabai, "Circularly polarised multiservice RFID antenna," IET Microwaves, Antennas Propag., vol. 11, no. 2, pp. 232-239, 2017.

[18] R. Caso, A. Michel, M. Rodriguez-Pino and P. Nepa, "Dual-band UHF-RFID/WLAN circularly polarized antenna for portable RFID readers," IEEE Trans. Antennas Propag., vol. 62, no. 5, pp. 2822-2826, 2014.

[19] M. Kaur, M. Sandhu, N. Mohan, and P. S. Sandhu, "RFID Technology Principles, Advantages, Limitations \& Its Applications," Int. J. Comput. Electr. Eng., vol. 3, no. 1, pp. 151-157, 2011.

[20] F. Liu, R. Jiang and Y. HU, "RFID middleware and its application in warehouse management," Comput. Eng., vol. 13, no. 272-273, pp. 276, 2006

[21] K. Ahsan, H. Shah and P. Kingston, "RFID Applications: An Introductory and Exploratory Study." arXiv preprint arXiv: 1002. 1179, 2010.

[22] C. A. Balanis, ANTENNA THEORY ANALYSIS AND DESIGN, 3rd ed., Hoboken, New Jersey: John Wiley \& Sons, 2005.

[23] B. S. A. I. Sandeep, "Design and simulation of microstrip patch array antenna for wireless communications at 2.4 GHz," International Journal os Scientific \& Engineering Research, vol. 3, no. 11, pp. 1-5, 2012.

[24] D. G. Fang, Antenna Theory and Microstrip Antennas, CRC Press: Taylor and Francis Group, Boca Raton, 2010.

[25] A. K. Gautam, N. Agrawal and K. Rambabu, "Design and packaging of a compact circularly polarised planar antenna for 2. 45-GHz RFID mobile readers," IET Microwaves, Antennas \& Propagation, vol. 13, no. 13, pp. 2310 2314, 2019.

[26] N. O. Parchin, H. J. Basherlou, R. A. Abd-Alhameed and J. M. Noras, "Dual-band monopole antenna for RFID applications," Futur. Internet, vol. 11, no. 2, p. 31, 2019.

[27] M. Z. A. A. Aziz et al., "Printed omnidirectional antenna for RFID applications," in 2013 IEEE International Conference on RFID-Technologies and Applications (RFID-TA), 2013, pp. 1-4.

[28] M. R. Reader, "A Compact and Broadband Microstrip Stacked Patch Antenna With Circular Polarization for 2.45GHz Mobile RFID Reader," IEEE Antennas and Wireless Propagation Letters, vol. 12, pp. 623-626, 2013. 
[29] Z. J. Tang and Y. G. He, "Broadband microstrip antenna with U and T slots for 2.45/2.41GHz RFID tag," Electron. Lett., vol. 45, no. 18, pp. 926-928, 2009.

[30] M. H. Mokhtar, M. K. A. Rahim, N. A. Murad and H. A. Majid, "A compact slotted microstrip patch antenna for RFID applications," 2013 IEEE Int. Conf. RFID-Technologies Appl. RFID-TA 2013, pp. 4-5, 2013.

[31] M. Ihamji, E. Abdelmounim, J. Zbitou, H. Bennis, M. Latrach, "A compact miniature fractal planar antenna for RFID readers," Indonesian Journal of Electrical Engineering and Computer Science, vol. 15, no. 1 pp. 300-305, 2019.

[32] A. El Hamraoui, E. H. Abdelmounim, J. Zibtou, H. Bennis and M. Latrach, "A New Compact CPW-Fed Dual-Band Monopole Antenna for RFID Applications, " Indonesian Journal of Electrical Engineering and Computer Science, vol.8, no. 1, pp. 69-76, 2017.

[33] V. Ramesh Kumar and S. DK, "A Compact Inverted Y Slot Rectangular Microstrip Patch Antenna for Bluetooth Applications," Indonesian Journal of Electrical Engineering and Computer Science, vol. 11, no. 2, pp. 413-418, 2018.

[34] I. Mohamed, A. E, B. Hamid, H. M and L. M, "A Miniature L-slot Microstrip Printed Antenna for RFID," TELKOMNIKA (Telecommunication Computing Electronics and Control), vol. 16, no. 5, pp. 1923-1930, 2018.

[35] A. El Hamraoui, E. H. Abdelmounim, J. Zibtou, H. Bennis and M. Latrach, "A New Design of a Compact CPWFed Dual-Band Printed Antenna for RFID Applications,". in International Conference on Wireless Networks and Mobile Communications (WINCOM), pp.1-4, 2015.

[36] R. Er-rebyiy, et al, "New Miniature Planar Microstrip Antenna Using DGS for ISM applications," TELKOMNIKA (Telecommunication Computing Electronics and Control), vol. 15, no.3, pp. 1149-1154, 2017.

[37] A. Ennajih, J. Zbitou, M. Latrach, A. Errkik, L. El Abdellaoui, A. Tajmouati, "Dual Band Metamaterial Printed Antenna Based on CSRR for RFID Applications," International Journal of Microwave and Optical Technology, vol. 12, no. 2, pp. 106-113, 2017

[38] B. Niboriya, C. Choudhary and G. Prabhakar, "S-shape Wideband Microstrip Patch Antenna with Enhanced Gain and Bandwidth for Wireless Communication," Int. J. Comput. Appl., vol. 73, no. 7, pp. 975-8887, 2013.

\section{BIOGRAPHIES OF AUTHORS}

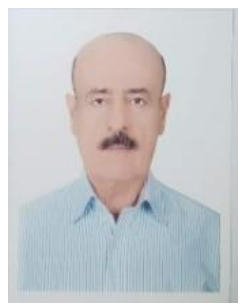

Sufyan Haza Ali was born in Tikrit- Iraq on the seventh of july 1955. He received his BSc. Electronics and Radio Engineering at Kiev Engineering Collage in Soviet Union 1979. He received his Ph.D. degree from Kiev Engineering Collage in Soviet Union 1990. Now he is lecture in Electrical Engineering Department - Tikrit University- Iraq. He has authored of several papers in international / national Journals. His research interests in Communication and Radar Engineering.

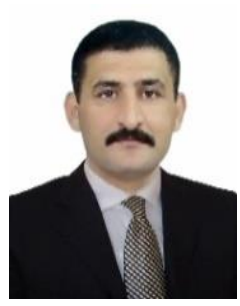

Ahmed Hameed Reja was born in Baghdad-Iraq on the eighth of January 1971. He received his BSc. Electrical and Electronics Engineering - Communication Department at Al - Rasheed College of Engineering - University of Technology-Baghdad - Iraq in 1995, and M.Sc. Electrical and Electronics Engineering - Communication and Microwave field from University of Technology, Baghdad - Iraq in 2002. He is a faculty member in the Department of Electromechanical Engineering at University of Technology. He received his Ph.D. degree from Department of Electronics and Communication Engineering - Jamia Millia Islamia, New Delhi India in 2015. Now he is a head of Navigation and Guidance Engineering branch in University of Technology- Baghdad - Iraq. He has authored of several papers and book chapters in international / national Journals and proceedings of conferences. His research interests in Communication and Microwave Engineering.

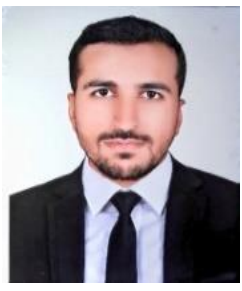

Yousif Azzawi Hachim was born in Salah ALdin-Iraq on the twenty-eighth of February 1995. He received his BSc. Electrical Engineering Department at Tikrit University - Salah ALdin - Iraq in 2017. He is a faculty study M.Sc. in the Department of Electrical Engineering - in Tikrit University, Salah ALdin - Iraq. 